\title{
Regional and Socioeconomic Differences in the Coverage of the Papanicolau Test in Brazil: Data from the Brazilian Health Survey 2013
}

\section{Diferenças regionais e socioeconômicas na cobertura do exame Papanicolau no Brasil: Dados da Pesquisa Nacional de Saúde 2013}

\begin{abstract}
Isabelle Ribeiro Barbosa ${ }^{1}$
${ }^{1}$ Collective Health, Faculdade de Ciências da Saúde do Trairi, Universidade Federal do Rio Grande do Norte, Santa Cruz, RN, Brazil

Address for correspondence Isabelle Ribeiro Barbosa, PhD, Professor, Faculdade de Ciências da Saúde do Trairi, Universidade Federal do Rio Rev Bras Ginecol Obstet 2017;39:480-487. Grande do Norte, Rua Vila Trairi, S/N, Centro, 59200-000 Santa Cruz, RN, Brazil (e-mail: isabelleribeiro@oi.com.br).
\end{abstract}

\section{Abstract \\ Keywords \\ - papanicolaou test \\ - cervical neoplasms \\ - women's health \\ - early detection of cancer \\ - inequalities in health \\ - epidemiology}

\section{Resumo}

Purpose To evaluate the coverage of the Papanicolaou test in Brazil and the associated factors.

Methods Cross-sectional study based on data from the Brazilian Health Survey 2013 comprising the proportion of 25- to 64-year-old women who had undergone a Papanicolaou test within the previous 3 years, categorized by sociodemographic variables and access to healthcare services.

Results The screening coverage in Brazil was of $79.4 \%$ ( $95 \%$ confidence interval [ $95 \% \mathrm{Cl}]$ : 78.4-80.3), showing significant differences between the different states of the country, with the highest rate in the state of Roraima (86.5; 95\%Cl: 83.5-89.4), and the lowest one in the state of Maranhão $(67.7 ; 95 \% \mathrm{Cl}: 61.3-74.0)$. Undergoing the test was significantly more frequent among married women $(83.6 \% ; 95 \% \mathrm{Cl}: 82.4-84.8)$, those with higher educational levels (88.7\%; 95\%Cl: 87.0-90.5), of white ethnicity (82.6\%; $95 \% \mathrm{Cl}: 81.3-83.9)$ and who reside in urban areas $(80.1 \%$; $95 \% \mathrm{Cl}: 79.1-81.2)$. Those who had undergone the test more than three years prior to the survey and the ones who had never undergone it were associated with a lower level of education, being of black or brown ethnicity, single or divorced, and rural dwellers.

Conclusions The coverage of cervical cancer screening in Brazil is below the recommended rate and presents regional and sociodemographic disparities.

Objetivo Avaliar a cobertura do exame Papanicolau no Brasil e os fatores associados. Métodos Estudo transversal a partir dos dados da Pesquisa Nacional de Saúde 2013 relativos à proporção de mulheres de 25 a 64 anos que realizaram pelo menos um exame Papanicolau nos últimos 3 anos, categorizados por variáveis sociodemográficas e de acesso aos serviços de saúde. received January 21, 2017 accepted May 23, 2017 published online August 7, 2017 ISSN $0100-7203$.
Copyright (e 2017 by Thieme Revinter

Publicações Ltda, Rio de Janeiro, Brazil
License terms

(c) $(1) \$$ 
Palavras-chave

- teste de Papanicolau

- neoplasias do colo do útero

- saúde da mulher

- detecção precoce de câncer

- desigualdades em saúde

- epidemiologia
Resultados A cobertura do rastreio foi de $79,4 \%$ no Brasil (intervalo de confiança de $95 \%$ [IC $95 \%]$ : 78,4-80,3), com diferença significativa entre as unidades federativas, sendo maior no estado de Roraima (86,5\%; IC $95 \%$ : 83,5-89,4) e menor no Maranhão $\left(67,7 \%\right.$; $I C_{95 \%}$ : $61,3-$ 74,0). A realização do exame foi significativamente maior entre as mulheres casadas (83,6\%; IC 95\%: 82,4-84,8), com nível de instrução mais elevado (88,7\%; IC $95 \%$ :87,0-90,5), de etnia branca (82,6\%; $\left.I C_{95 \%}: 81,3-83,9\right)$, e que residem em área urbana $\left(80,1 \%\right.$; $I C_{95 \%}$ : $79,1-81,2)$. As que realizaram o exame havia mais de 3 anos e as que nunca realizaram estiveram associadas a menor nível de instrução, a mulheres negras e pardas, a ser solteira ou separada, e a moradoras de área rural.

Conclusões A cobertura do rastreio para o câncer e colo de útero no Brasil tem proporção abaixo da recomendada, e apresenta disparidades regionais e sociodemográficas.

\section{Introduction}

Cervical cancer is the third most common type of cancer in women, and one of the leading causes of cancer death among women worldwide. ${ }^{1}$ With an estimated 529,000 cases and 275,000 deaths per year, the burden of cervical cancer varies considerably among countries, with more than $85 \%$ of the global burden of the disease distributed in low- and middleincome countries. ${ }^{2}$ The disparity in the incidence and mortality of cervical cancer between low- and high-income countries and the inequalities within each country are mainly related to the prevalence of human papillomavirus (HPV) infection, and to differences in the access to screening and in the treatment of malignant lesions. ${ }^{3}$

Performing a periodic cervical cytopathology examination is the primary screening strategy for cervical cancer and its precursor lesions, because of the acceptable sensitivity and specificity, low cost, safety in the execution and acceptance by women. ${ }^{4}$ The evolution of an incipient cervical lesion to an invasive form is slow, and can extend for up to 20 years. This feature enables the effective control of the malignant neoplasm through proper screening. ${ }^{5}$

The introduction of the high-quality screening test using cytology (Papanicolaou test, also called Pap test) has led to a marked reduction in the mortality from cervical squamous cell cancer, which accounts for 80 to $90 \%$ of cervical cancers. Since its introduction in the United States in the mid-1950's, cervical cancer, then the most common cause of cancer death in women, now ranks 14 th among deaths due to cancer in the country. ${ }^{6}$

In 2011, the American Cancer Society (ACS), in collaboration with other associations, reiterated by consensus the recommendation to perform the screening test for the prevention and early detection of precancerous lesions and cancer itself. The ACS consensus recommends that the exam be performed for women aged between 21 and 65 years, with a 3-year interval for those with negative cytology. ${ }^{7}$ Following the recommendations of the World Health Organization (WHO), the Brazilian Cancer Institute established, as a guideline for cervical cancer screening, the performance of the Pap test in women aged between 25 and 64 years, with a 3 -year interval between examinations after 2 negative annual tests, to be discontinued after the age of 64 , for those women who have had at least 2 consecutive negative tests in the previous 5 years. ${ }^{8,9}$

According to the recommended protocols, the minimum coverage for the test should reach $80 \%$ of the target population. However, Brazil still does not have a population-based information system, a crucial item for organized tracking. As a direct consequence of this, there is no control of the women who undergo the examinations, or of the periodicity with which they do it, which characterizes the country in an opportunistic tracking scenario. ${ }^{9-11}$

The high incidence and mortality due to this type of cancer among women in Brazil indicates that the measures adopted to track this disease may not be leading to the expected results. ${ }^{2}$ In recent years, a reduction in cervical cancer mortality has been observed in Brazil, but the magnitude of this reduction has been unequally distributed among the Brazilian regions. ${ }^{12}$ Aspects related to the inequalities in the supply of and access to the screening examination have been widely studied, and they represent a restrictive step for the control of cervical cancer in several regions of the country. ${ }^{13}$

In Brazil, the National Program for Cervical Cancer Control aims to ensure the access to the preventive examination for women in the priority age group, qualification of diagnosis, and to provide treatment for precursor lesions. Despite the improvement achieved in mortality indicators, this reduction is below the expectations. ${ }^{14}$

Recognizing the scope of a preventive program and the factors related to the low adherence to the proposed model can contribute to the development of more effective public policies, in line with the territorial reality. Identifying inequalities is a key aspect in the monitoring and evaluation of women's healthcare policies.

The objective of this study was to analyze the inequalities in the coverage of cervical cancer screening in Brazil and the social and economic factors related to the non-adherence to the current preventive program.

\section{Methods}

This is a cross-sectional descriptive study with data from the Brazilian Health Survey 2013 (Pesquisa Nacional de Saúde [PNS, in the Portuguese acronym] 2013), ${ }^{15}$ conducted by the Brazilian Institute of Geography and Statistics (IBGE, in the Portuguese 
acronym) in partnership with the Brazilian Ministry of Health (BMH) and Oswaldo Cruz Foundation (Fiocruz, in the Portuguese acronym). The research population was composed of adults (aged $\geq 18$ years) living in private households throughout the country, and those living in tents, military bases, lodges, boats, penitentiaries, penal colonies, prisons, jails, asylums, orphanages, convents and hospitals were excluded.

The sample size was defined considering the desired precision level for the estimates of some indicators of concern. The minimum size defined for the sample was 1,800 households per state. The PNS chose a total of 81,187 households randomly, with 1 individual selected per household. After completing the collection of data, interviews were conducted in 64,348 households, which resulted in a non-response rate of $8.1 \%$.

The sampling plan employed was the three-stage cluster sampling, with stratification of the primary sampling units. The census tracts make up the primary sampling units (PSUs), the households represent second-stage units, and the adult dwellers are the third-stage units.

Sampling weights were defined for the PSUs, the households and all their dwellers, as well as the weight for the selected resident. The latter was calculated considering the weight of the corresponding household, the probability of the resident's selection, adjustments related to non-response by sex, and calibration by total population according to sex and age groups, estimated by the weight of all residents.

All considerations regarding the sampling plan, weighting and effects of the PNS delineation are contained in the publications by Souza-Júnior et al and Damacena et al. ${ }^{16,17}$

The PNS questionnaire was divided into modules that address characteristics of the household, of all residents (schooling, income, work, people with disabilities, coverage of healthcare insurance, use of healthcare services, health of children under 2 years of age, health of the elderly), and of the selected adult population (lifestyles, perception of health status, accidents and violence, chronic diseases, women's health, prenatal care, oral health and medical care).

By means of Module R, the PNS addressed the topic 'women's health,' including questions on preventive testing, reproductive history and family planning. The issues of interest in the present study are related to the proportion (\%) of 25- to 64-year-old women who underwent a screening examination for cervical cancer. For the purpose of the present study, the analyzed variable was: 'When was the last time you underwent a screening test for cervical cancer?' It was categorized into 'Proportion of 25- to 64-year-old women who had undergone the examination within the 3 years prior to the survey,' 'Proportion of 25- to 64-year-old women who had undergone the examination more than 3 years prior to the survey,' and 'Proportion of 25- to 64-year-old women who had never undergone the test.' For the calculation of these indicators, the number of women between 25 and 64 years of age who reported never having had sex was used as the denominator.

The proportions of the sample that underwent the cytopathology examination, presented in percentages (\%) with their respective $95 \%$ confidence intervals ( $95 \% \mathrm{Cls}$ ), were estimated for the population of women between the ages of 25 and 64 who had already had sex, according to the sociodemographic variables and the variables on the access to the health service. The following variables were used in the description: states (26 states and the Federal District), level of education (no schooling/incomplete elementary school; complete elementary school/incomplete high school; complete high school/ incomplete higher education; complete higher education); ethnicity/ skin color (white, black and brown); civil status ( single, married, separated, divorced, widowed); place of residence (urban and rural), coverage of the examination (public and private healthcare networks); the time it took to get the result; and the reason mentioned for the failure to perform the examination. The data were tabulated using the Tabnet tool (IT Depart in SUS, Health Ministery. Available at: http://tabnet.datasus.gov.br) on the website of the Computer Science Department of the Brazilian Unified Healthcare System (Datasus, in the Portuguese acronym), and were expressed in percentages with their 95\%CIs. In order to make the tables and figures, the data were organized into Microsoft Excel 2010 (Microsoft Corporation, Redmond, WA, US) spreadsheets.

The PNS project was approved by the Brazilian Commission for Research Ethics (Conep, in the Portuguese acronym) on July 8,2013 , under number 10853812.7.0000.0008. This current study is a research that used secondary data available on official websites of the $\mathrm{BMH}$, and was exempted from evaluation by a research ethics committee, in accordance with Resolution 466/2012 of the Brazilian Health Council.

\section{Results}

Among the Brazilian women aged 25-64 years, 79.4\% (95\%CI: 78.4-80.3) reported having undergone at least 1 cervical cancer screening test within the 3 years prior to the survey. There was a significant difference in the coverage percentage among the states: it was higher in the states of Roraima (95\%CI: 83.5-89.4), Santa Catarina (95\%CI: 80.5-88.5), and Espírito Santo (95\%CI: 79.9-88.5), while the states with the lowest percentages were Maranhão (95\%CI: 61.3-74.0), Amapá (95\%CI: 64.0-73.6), and Ceará (95\%CI: 65.2 -72.8), as shown in - Fig. 1.

The percentages of women aged 25-64 years in Brazil who reported never having undergone the screening test, or who had undergone the test more than 3 years prior to the survey were 9.03\% (95\%CI: 8.31-9.74) and 11.6\% (95\%CI: $10.90-$ 12.29) respectively. The states that presented the highest percentages of examinations performed more than 3 years before the survey were Amapá (95\%CI: 13.93-22.20), Sergipe (95\%CI: 13.56-20.67), Maranhão (95\% CI: 12.88-21.25), and Ceará (95\%CI: 12.91-19.57), with a significant difference in relation to the other states. It should be noted that the nine states of the Northeast region presented this marker with percentages above the observed national mean (-Fig. 2 ).

The proportion of women aged 25-64 years who had never undergone the cervical cancer screening test was significantly higher in the states of Pará (95\%Cl: 12.09-20.08), Alagoas (95\% CI: 11.60-19.07), Maranhão (95\%CI: 9.92-20.60), and Paraíba (95\%Cl: 11.18-18.38). Of the eleven states that presented these proportions above the national mean, seven belong to the Northeast region of Brazil (-Fig. 3). 


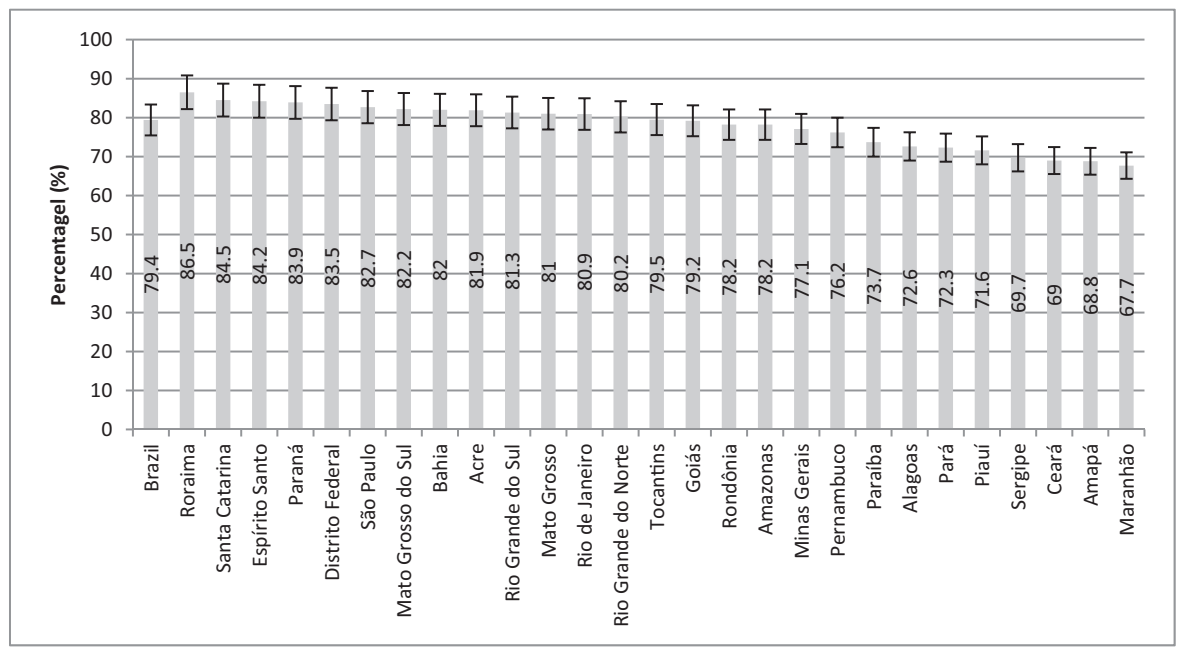

Fig. 1 Percentage of 25- to 64-year-old women who underwent the cytopathology examination within the past 3 years in Brazil as a whole, in the different states, and in the Federal District. Source: Brazilian Health Survey, $2013 .{ }^{15}$ Note: The bars represent the $95 \%$ confidence intervals of the percentages presented.

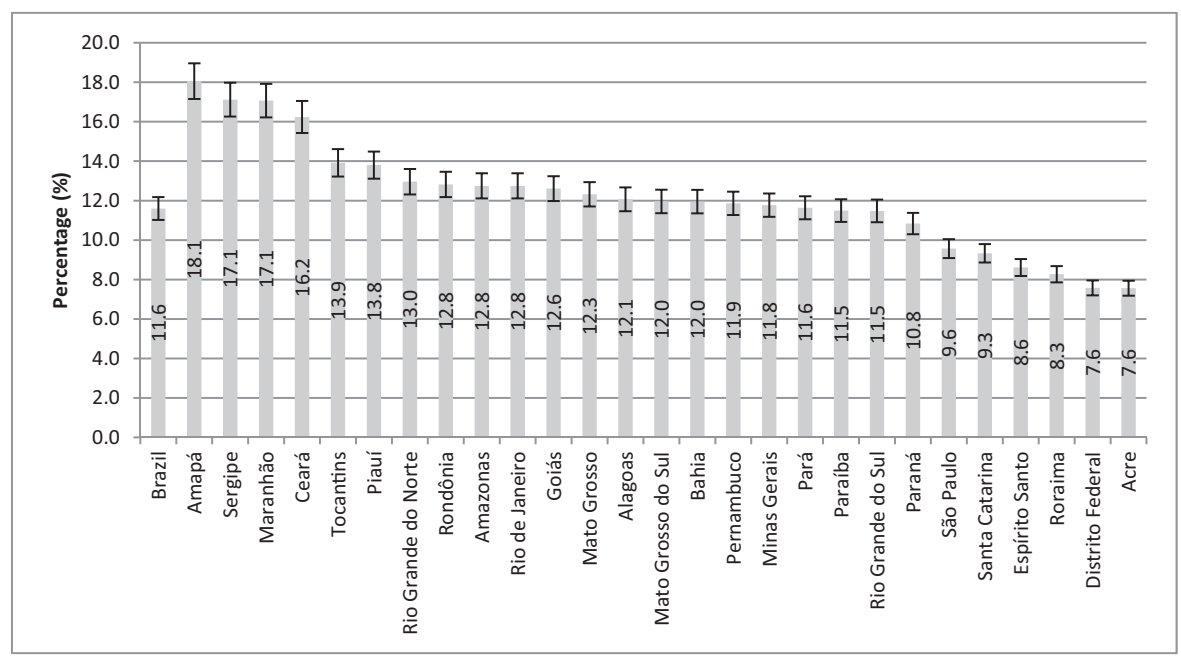

Fig. 2 Percentage of women aged 25 to 64 years who underwent cytopathology examination more than 3 years ago in Brazil as a whole, in the different states, and in the Federal District. Source: Brazilian Health Survey, 2013. ${ }^{15}$ Note: The stems represent the $95 \%$ confidence intervals of the percentages presented.

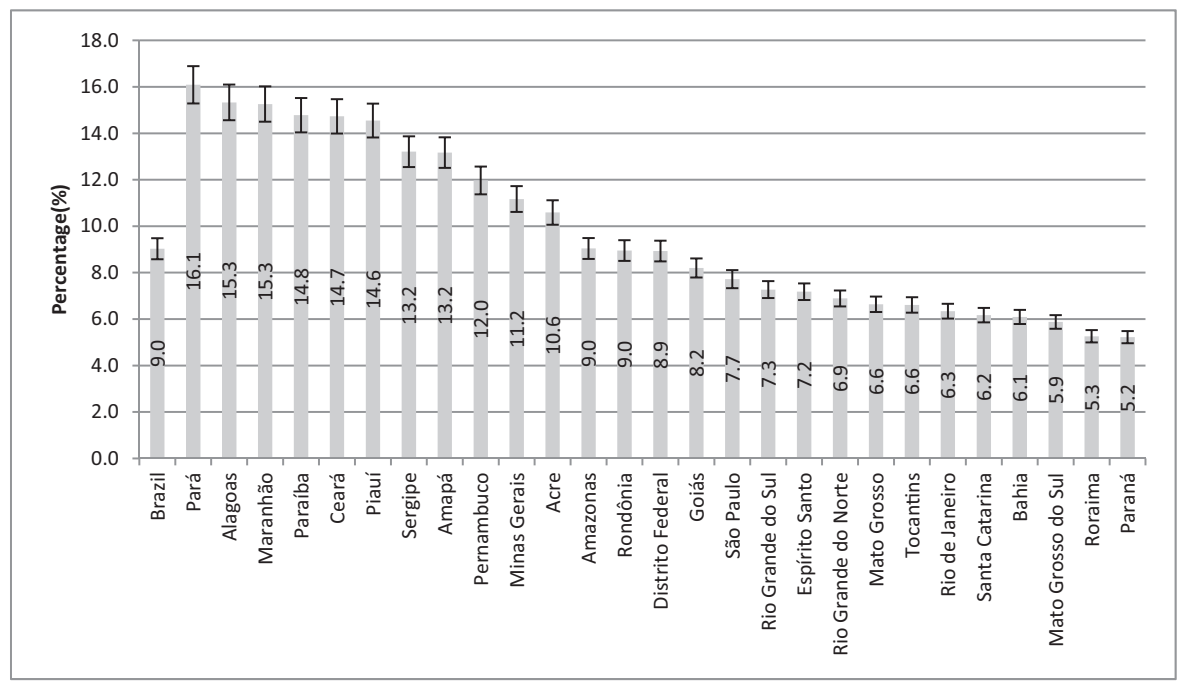

Fig. 3 Percentage of women aged 25 to 64 years who have never undergone the cytopathology examination in Brazil as a whole, in the different states, and in the Federal District. Source: Brazilian Health Survey, $2013 .{ }^{15}$ Note: The stems represent the $95 \%$ confidence intervals of the percentages presented. 
- Table 1 shows the proportion of women who underwent screening for cervical cancer according to sociodemographic factors and access to health services. The screening within the 3-year period before the study was significantly higher among married women (83.6\%; 95\%CI: 82.4-84.8), those who presented the two highest levels of education $(88.7 \%$; 95\%CI: 87.0-90.5, with complete higher education; and 83.3\%; 95\%CI: 81.8-84.8,with complete high school and incomplete higher education), those with white skin color/ ethnicity (82.6\%; 95\%CI: 81.3-83.9), and among those living in urban areas (80.1\%; 95\%CI: 79.1-81.2). Having healthcare insurance as a means of accessing the test was related to a higher proportion of women who underwent at least 1 examination within the last 3 years $(93.4 \%$; 95\%CI: 92.594.4). The results of the test arrived within $\sim 3$ months for most women who underwent the screening test up to 3 years prior to the survey.

As for the women who underwent the Pap test more than 3 years before the survey, the percentages were higher among widows (18.12\%; 95\%CI: 14.87-21.37) and separated women (17.62\%; 95\%CI: 12.11-23.12), those with no schooling or incomplete elementary school (15.82\%; 95\%CI: 14.56-17.08), and those with brown skin color/ethnicity $(13.24 \%, 95 \% \mathrm{CI}$ : 12.15-14.32) compared with those with white skin color/

Table 1 Coverage of cervical cancer screening according to sociodemographic variables and access to the healthcare services. Brazilian Health Survey, $2013^{15}$

\begin{tabular}{|c|c|c|c|}
\hline Variables & $\begin{array}{l}\text { Pap test within } \\
\text { the past } 3 \text { years }\end{array}$ & $\begin{array}{l}\text { Pap test more } \\
\text { than } 3 \text { years ago }\end{array}$ & $\begin{array}{l}\text { Never underwent } \\
\text { Pap test }\end{array}$ \\
\hline & $\begin{array}{l}\text { Percentage } \\
(95 \% \mathrm{Cl})\end{array}$ & $\begin{array}{l}\text { Percentage } \\
(95 \% \mathrm{Cl})\end{array}$ & Percentage $(95 \% \mathrm{Cl})$ \\
\hline \multicolumn{4}{|l|}{ Civil status } \\
\hline Married & $83.6(82.4-84.8)$ & $10.47(9.52-11.43)$ & $5.89(5.13-6.65)$ \\
\hline Separated & $71.9(64.9-78.9)$ & $17.62(12.11-23.12)$ & $10.51(4.62-16.39)$ \\
\hline Divorced & $80.9(77.4-84.4)$ & $14.41(11.08-17.74)$ & $4.71(3.21-6.20)$ \\
\hline Widow & $72.9(69.0-76.9)$ & $18.12(14.87-21.37)$ & $8.95(6.56-11.34)$ \\
\hline Single & $74.9(73.3-76.4)$ & $11.08(10.05-12.11)$ & $14.06(12.72-15.41)$ \\
\hline \multicolumn{4}{|l|}{ Educational level } \\
\hline No schooling or incomplete elementary school & $72.1(70.5-73.8)$ & $15.82(14.56-17.08)$ & $12.04(10.81-13.27)$ \\
\hline Complete elementary school and incomplete high school & $77.8(75.2-80.3)$ & $13.32(11.23-15.40)$ & $8.92(7.28-10.56)$ \\
\hline Complete high school and incomplete higher education & $83.3(81.8-84.8)$ & $8.48(7.40-9.57)$ & $8.21(7.03-9.38)$ \\
\hline Complete higher education & $88.7(87.0-90.5)$ & $7.11(5.70-8.52)$ & $4.14(3.06-5.22)$ \\
\hline \multicolumn{4}{|l|}{ Skin color or ethnicity } \\
\hline White & $82.6(81.3-83.9)$ & $10.31(9.33-11.28)$ & $7.05(6.07-8.02)$ \\
\hline Black & $77.4(74.1-80.8)$ & $11.11(9.02-13.20)$ & $11.45(8.39-14.51)$ \\
\hline Brown & $75.9(74.4-77.4)$ & $13.24(12.15-14.32)$ & $10.87(9.78-11.96)$ \\
\hline \multicolumn{4}{|l|}{ Place of residence } \\
\hline Urban & $80.1(79.1-81.2)$ & $11.52(10.77-12.28)$ & $8.34(7.57-9.10)$ \\
\hline Rural & $74.1(71.6-76.6)$ & $12.10(10.32-13.89)$ & $13.82(11.95-15.70)$ \\
\hline \multicolumn{4}{|l|}{ Origin of the examination } \\
\hline Brazilian Unified Healthcare System & $83.6(82.5-84.8)$ & $16.37(15.24-17.50)$ & - \\
\hline Private & $89.4(87.8-91.0)$ & $10.58(8.95-12.21)$ & - \\
\hline Healthcare insurance & $93.4(92.5-94.4)$ & $6.56(5.61-7.51)$ & - \\
\hline \multicolumn{4}{|l|}{ Period it took the test result to arrive } \\
\hline Within 1 month after the examination & $88.7(87.8-89.6)$ & $11.27(10.36-12.18)$ & - \\
\hline Between 1 and 3 months after the examination & $85.0(83.5-86.6)$ & $14.98(13.41-16.54)$ & - \\
\hline Between 3 and 6 months after the examination & $83.7(80.0-87.5)$ & $16.25(12.46-20.04)$ & - \\
\hline More than 6 months after the examination & $73.5(61.8-85.2)$ & $26.50(14.78-38.23)$ & - \\
\hline Has never received & $71.4(63.0-79.9)$ & $28.57(20.10-37.04)$ & - \\
\hline Has never tried to get the result & $57.6(47.0-68.1)$ & $42.44(31.87-53.00)$ & - \\
\hline
\end{tabular}

Abbreviation: $95 \% \mathrm{Cl}, 95 \%$ confidence interval. 
Table 2 Reasons mentioned for failure to undergo cervical cancer screening in Brazil. Brazilian Health Survey, $2013^{15}$

\begin{tabular}{|l|l|}
\hline Reasons & Percentage (\%) - 95\% Cl \\
\hline Not thinking it is necessary & $49.12(45.33-52.91)$ \\
\hline Being ashamed & $10.5(8.33-12.67)$ \\
\hline $\begin{array}{l}\text { Never being instructed } \\
\text { to undergo the exam }\end{array}$ & $22.32(18.74-25.90)$ \\
\hline Having financial difficulties & $1.34(0.71-1.97)$ \\
\hline $\begin{array}{l}\text { Had difficulty making } \\
\text { an appointment }\end{array}$ & $4.08(2.80-5.37)$ \\
\hline $\begin{array}{l}\text { The waiting time in the } \\
\text { healthcare service is too long }\end{array}$ & $1.84(1.06-2.62)$ \\
\hline Others & $10.8(8.63-12.69)$ \\
\hline
\end{tabular}

Abbreviation: 95\%Cl, 95\% confidence interval.

ethnicity $(10.31 \%, 95 \%$ CI 9.33-11.28). There was no statistically significant difference with regard to the place of residence. There was a greater proportion of this inadequate coverage when the Brazilian Unified Healthcare System (SUS, in the Portuguese acronym) was the means of accessing the last examination (16.37\%; 95\%CI: 15.24-17.50). Most of these women reported they had never tried to get the result, or had never received it. In that group, $26.50 \%$ of the women received the result 6 months after the examination.

Never having performed the cytopathology examination was more prevalent among single women (14.06\%; 95\%CI: $12.72-$ $15.41)$, those with no schooling or with incomplete elementary school (12.04\%; 95\%Cl: 10.81-13.27), and among black women (11.45\%; 95\%CI: 8.39-14.51) compared with white women (7.05\%; 95\%CI: 6.07-8.02), and among those living in rural areas (13.82\%; 95\%Cl: 11.95-15.70). The main reasons for not undergoing the test were: "not finding it necessary" (49.12\%; 95\% CI: 45.33-52.91) and "never being instructed to undergo the test" (22.32\%; 95\%CI: 18.74-25.90) (-Table 2).

\section{Discussion}

The results of the present study demonstrate that there is a marked regional and socioeconomic inequality in the coverage of the cytopathology examination in Brazil. They also show that the percentage of the coverage is below that which is recommended by the World Health Organization (WHO).

Despite this, some studies have reported a significant increase in the coverage rate of the exam in Brazil in the last decades. In a systematic review that described the Pap smear coverage in Brazil between the 1980's and 2000's, which was based on population-based cross-sectional studies, it was indicated that the coverage of the examination in Brazil ranged from 60 to $77 \%$, regarding the execution of at least 1 test in the last 3 years prior to the survey. ${ }^{18}$ A study performed in the state of Santa Catarina in 2009 recorded that the coverage rate of this exam was $86 \%{ }^{19} \mathrm{~A}$ comparison between the coverage rate in the city of São Paulo in 1987 and 2002 showed a 24\% increase in prevalence, which ranged from 68.8 to $85 \%$ along the years studied. ${ }^{20}$ In the city of Boa Vista, in the state of Roraima, a cross-sectional study ${ }^{13}$ based on a household survey reported a prevalence of $85.7 \%$ (95\%CI: 82.5-88.5). The evolution of this indicator for Brazil can also be confirmed by comparing the results of the present study, which indicated a $79.4 \%$ coverage rate for the examination performed within the 3 years prior to the survey (IBGE, 2013), ${ }^{15}$ to the data obtained in the National Household Sampling Survey (PNAD, in the Portuguese acronym) in 2003 , which registered a $65.5 \%$ coverage rate among women aged between 18 and 69 years. ${ }^{21}$

The reduction in the mortality rate due to cervical cancer in Brazil in the last decades may be a consequence of the Pap test coverage expansion, since mortality is attenuated because of a better access to diagnostic and therapeutic measures. Barbosa et $\mathrm{al}^{2}$ observed a downward trend in cervical cancer mortality rates in Brazil between 1996 and 2010, at the proportion of $1.7 \%$ per year, with the highest reduction rates observed for the South (annual percentage change $[\mathrm{APC}]=-3.9 \%$ ), Southeast $(\mathrm{APC}=-3.0 \%)$ and Midwest $(\mathrm{APC}=-2.0 \%)$ regions. With similar results, the study by Girianelli et al $^{12}$ reported that, between 1980 and 2010, the drop in cervical cancer mortality occurred for all women in the Southeast and South, the most developed regions in the country, but reached only women living in the capitals of the North and Northeast regions. In several parts of the world, the incidence and risk of cervical cancer mortality has declined. In developed countries, the number of new cases has been reduced by $\sim 80 \%$ because of an effective program for the detection and treatment of precancerous lesions. $^{22}$

These results raise the hypothesis that, although there has been progress in the coverage rate of the cervical cancer screening test in Brazil, and a reduction in mortality rates for cervical cancer, the expansion of the Pap test coverage may not have developed in the same way among the Brazilian regions.

This hypothesis can be corroborated by the findings of the present study, which demonstrate that the states in the North and Northeast of Brazil recorded the lowest percentage of examinations performed within the last three years, in addition to the greater percentage of women who had never taken the test, which demonstrates the intense inequality in the Pap test coverage among the Brazilian regions.

In Brazil, the access of the population to different levels of healthcare is one of the meanings attributed to comprehensiveness. Even though the constitutional guarantee of universal access to healthcare has overcome formal barriers, difficulties related to the access and continuity of care remain in both basic care and specialized services. The organization based on spontaneous demand, a basic characteristic of the private healthcare model, is traditionally found in public healthcare services in the country. ${ }^{23}$ Brazilian studies show that most women who undergo the Pap test do it spontaneously, and that emphasizes the relationship between opportunistic tracking and the low coverage rate of the examinations, often with excess examinations in some women, and the exclusion of others, probably the ones that would most benefit from the test. ${ }^{11,13,24}$

One of the factors that contribute the inefficiency of an unorganized program in Brazil is the difficulty related to diagnostic confirmation, follow-up and treatment of the 
tracked cases. The information systems of the SUS are based on procedures and not on the person, as is the case with the Brazilian Cervical Cancer Information System (Siscolo, in the Portuguese acronym), which records the cytological exams with altered diagnoses performed in Brazil, but does not allow the screening history of these women to be recorded and, consequently, does not allow the identification of the ones who are not engaged in control or who underwent the test three or more years ago. ${ }^{10}$

In spite of the adequacy of the structure and work process of the basic care teams in Brazil in the prevention of cervical cancer, the results show that only half of all health units that compose the basic care network in Brazil has adequate structures for cervical cancer screening by means of cytopathology examination, and only $30 \%$ of the teams were classified with an adequate working process for the detection of cervical cancer. ${ }^{25}$

However, with the increased coverage of the cytological examination, two different phenomena, closely linked to differences in conditions of access, use and performance of health services, can be observed. On the one hand, there is the drop in the mortality rate in regions where social health conditions can ensure treatment and follow-up for all patients with altered exams, rendering possible the cure of the disease. On the other hand, there is the increased mortality rate in less developed regions, where cure cannot be guaranteed, or where the adherence of the target population is still limited, thus determining that part of the patients will only be cared for at an advanced stage of the disease, with few possibilities of cure. ${ }^{26}$

Therefore, it is important to recognize that, for the analysis of the reduction seen in cervical cancer incidence and mortality rates, other relevant points should be considered in conjunction with the Pap test coverage, such as the quality of the cervical cytology screening examinations that are performed, the access to services for biopsy and diagnostic confirmation, diagnostic examinations to stage confirmed cases, and access to cancer treatment: surgery, radiotherapy and chemotherapy. ${ }^{14}$

In the present study, undergoing the Papanicolaou test was closely related to the women's socioeconomic characteristics: those who underwent the examination more than 3 years prior to the survey and those who never underwent it were associated with women with lower levels of education, single or separated, and living in rural areas. These findings are similar to those described in several studies in Brazil, which found that women without a stable union, with low income and schooling limited to the elementary school presented higher odds of not having undergone the test. ${ }^{13,27,28}$

These findings reinforce the hypothesis that women living in worse socioeconomic conditions were more likely to be diagnosed with advanced cervical cancer. ${ }^{29}$

It is believed that women with low schooling have less power to pressure the healthcare services into providing quality care. Additionally, a low level of education can lead to a lower level of information and understanding, thus resulting in poor adherence to prevention strategies, ${ }^{11}$ as it is evidenced that education increases the notion of the impor- tance of regular health assessments and, therefore, the propensity to perform them; moreover, education can improve the understanding of the information, enhance the communication with the doctor, and improve the interpretation of the results. ${ }^{30}$

Other findings that stand out are related to marital status and failure to take the Pap test. It is said that, in general, the prevention measure is performed in conjunction with routine gynecological, obstetric or family planning activities, so that women living with their partners are more likely to use the healthcare services. ${ }^{27,28,31}$

The data also indicate that, for an important part of the population, especially the low-income population, the lack of knowledge about the need to undergo the exam and the lack of orientation toward its execution represent risk factors for the non-adherence to the preventive program. This fact raises the need for screening expansion, aiming at the most vulnerable groups in society, and for the development of comprehensive and effective preventive strategies that are aligned with local realities and consider education actions for the target audience in the context of primary healthcare. ${ }^{13}$

\section{Conclusion}

The present study verified that the coverage of the cervical cancer screening test for Brazilian women aged 25 to 64 years was close to the goal recommended by the BMH. However, lower coverage was observed in the less-favored social groups, indicating the strong influence of socioeconomic, demographic and healthcare disparities, as well as lack of continuity in healthcare and education actions for the prevention of cervical cancer.

Healthcare services should provide clinical and gynecological assistance, guidance on the control of sexually transmitted diseases and cervical cancer, and assistance in conception and contraception. The supply of such services is directly linked to the control of several factors related to cervical cancer. However, the barriers to its control are mainly related to failures in the screening programs and to the difficulty in accessing healthcare procedures.

In the present study, the cross-sectional design did not enable the use of temporality as a criterion of causality, since risk and outcome factors were measured at the same time, and the reverse causality bias cannot be eliminated, which constitutes one of the limitations of this study. The subject covered is personal and intimate, related to women's reproductive health, and this may have influenced the results. However, the sample size and the correct research procedures adopted strengthen the reliability of the data. Because this is a population survey, this study enables the identification of the actual coverage of the Papanicolaou test, and not just the number of exams performed in the public healthcare system.

\section{References}

1 Singh GK, Azuine RE, Siahpush M. Global inequalities in cervical cancer incidence and mortality are linked to deprivation, low socioeconomic status, and human development. Int J MCH AIDS 2012;1(01):17-30 
2 Barbosa IR, Souza DLB, Bernal MM, Costa IdoC. Regional inequalities in cervical cancer mortality in Brazil: trends and projections through to 2030. Cien Saude Colet 2016;21(01):253-262

3 Tsu V, Jerónimo J. Saving the world's women from cervical cancer. N Engl J Med 2016;374(26):2509-2511

4 Manica ST, Drachler MdeL, Teixeira LB, et al. Socioeconomic and regional inequalities of pap smear coverage. Rev Gaucha Enferm 2016;37(01):e52287

5 Falcão GB, Ibiapina FLP, Feitosa HN, et al. Fatores associados à realização de citologia para prevenção de câncer do colo uterino em uma comunidade urbana de baixa renda. Cad Saude Colet 2014;22(02):165-172

6 Simard EP, Naishadham D, Saslow D, Jemal A. Age-specific trends in black-white disparities in cervical cancer incidence in the United States: 1975-2009. Gynecol Oncol 2012;127(03):611-615

7 Saslow D, Solomon D, Lawson HW, et al; ACS-ASCCP-ASCP Cervical Cancer Guideline Committee. American Cancer Society, American Society for Colposcopy and Cervical Pathology, and American Society for Clinical Pathology screening guidelines for the prevention and early detection of cervical cancer. CA Cancer J Clin 2012;62(03):147-172

8 Brasil. Instituto Nacional de Câncer José Alencar Gomes da Silva. Coordenação de Prevenção e Vigilância. Divisão de Detecção Precoce e Apoio à Organização de Rede. Diretrizes brasileiras para o rastreamento do câncer do colo do útero. Rio de Janeiro: INCA; 2016

9 World Health Organization. WHO guidelines for screening and treatment of precancerous lesions for cervical cancer prevention. Geneva: WHO; 2013

10 Vale DBAP, Morais SS, Pimenta AL, Zeferino LC. Assessment of the cervical cancer screening in the Family Health Strategy in Amparo, São Paulo State, Brazil. Cad Saude Publica 2010;26(02):383-390

11 Ribeiro L, Bastos RR, Vieira MdeT, Ribeiro LC, Teixeira MTB, Leite ICG. Opportunistic screening versus missed opportunities: nonadherence to Pap smear testing in women attending prenatal care. Cad Saude Publica 2016;32(06):e00001415

12 Girianelli VR, Gamarra CJ, Azevedo e Silva G. Disparities in cervical and breast cancer mortality in Brazil. Rev Saude Publica 2014; 48(03):459-467

13 Navarro C, Fonseca AJ, Sibajev A, et al. Cervical cancer screening coverage in a high-incidence region. Rev Saude Publica 2015;49:17

14 Sousa AMV, Teixeira CCA, Medeiros SD, et al. [Cervical cancer mortality in the state of Rio Grande do Norte, Brazil, 1996-2010: time trends and projections up to 2030]. Epidemiol Serv Saude 2016;25(02):311-322 Portuguese

15 Instituto Brasileiro de Geografia e Estatística [Internet]. Pesquisa Nacional de Saúde: 2013: acesso e utilização dos serviços de saúde, acidentes e violências: Brasil, grandes regiões e unidades da federação. Rio de Janeiro: IBGE; 2015 [cited 2016 Jan 12]. Available from: http://biblioteca.ibge.gov.br/visualizacao/livros/liv94074.pdf

16 Souza-Júnior PRB, Freitas MPS, Antonaci GA, Szwarcwald CL. Desenho da amostra da Pesquisa Nacional de Saúde 2013. Epidemiol Serv Saúde. 2015;24(02):207-216
17 Damacena GN, Szwarcwald CL, Malta DC, et al. O processo de desenvolvimento da Pesquisa Nacional de Saúde no Brasil, 2013. Epidemiol Serv Saúde. 2015;24(02):197-206

18 Martins LFL, Thuler LCS, Valente JG. [Coverage of the Pap smear in Brazil and its determining factors: a systematic literature review]. Rev Bras Ginecol Obstet 2005;27(08):485-492 Portuguese

19 Gasperin SI, Boing AF, Kupek E. Cervical cancer screening coverage and associated factors in a city in southern Brazil: a populationbased study. Cad Saude Publica 2011;27(07):1312-1322

20 Ozawa C, Marcopito LF. [Papanicolaou smear screening: coverage in two home surveys applied in the city of São Paulo in 1987 and 2001-2002]. Rev Bras Ginecol Obstet 2011;33(05):238-245 Portuguese

21 Novaes HMD, Braga PE, Schout D. Fatores associados à realização de exames preventivos para câncer nas mulheres brasileiras, PNAD 2003. Cien Saude Colet 2006;11(04):1023-1035

22 Forouzanfar MH, Foreman KJ, Delossantos AM, et al. Breast and cervical cancer in 187 countries between 1980 and 2010: a systematic analysis. Lancet 2011;378(9801):1461-1484

23 Brito-Silva K, Bezerra AFB, Chaves LDP, Tanaka OY. Integrality in cervical cancer care: evaluation of access. Rev Saude Publica 2014; 48(02):240-248

24 Diniz AS, Xavier MB, Braga PP, Guimarães EAA. Assistência à saúde da mulher na atenção primária: prevenção do câncer do colo do útero. Rev APS. 2014;16(03):333-337

25 Tomasi E, Oliveira TF, Fernandes PAA, et al. Structure and work process in the prevention of cervical cancer in Health Basic Attention in Brazil: Program for the Improvement of Access and Quality. Rev Bras Saude Mater Infant 2015;15(02):171-180

26 Gamarra CJ, Valente JG, Azevedo e Silva G. Magnitude of mortality from cervical cancer in the Brazilian Northeast and socioeconomic factors. Rev Panam Salud Publica 2010;28(02):100-106

27 Albuquerque KM, Frias PG, Andrade CLT, Aquino EML, Menezes G, Szwarcwald CL. Pap smear coverage and factors associated with non-participation in cervical cancer screening: an analysis of the Cervical Cancer Prevention Program in Pernambuco State, Brazil. Cad Saude Publica 2009;25(Suppl 2):S301-S309

28 Borges MFSO, Dotto LMG, Koifman RJ, Cunha MdeA, Muniz PT. Prevalence of uterine cervical cancer testing in Rio Branco, Acre State, Brazil, and factors associated with non-participation in screening. Cad Saude Publica 2012;28(06):1156-1166

29 Müller EV, Biazevic MGH, Antunes JLF, Crosato EM. Socioeconomic trends and differentials in mortality due to cervical cancer in the State of Paraná (Brazil), 1980-2000. Cien Saude Colet 2011; 16(05):2495-2500

30 Arrossi S, Ramos S, Paolino M, Sankaranarayanan R. Social inequality in Pap smear coverage: identifying under-users of cervical cancer screening in Argentina. Reprod Health Matters 2008;16(32):50-58

31 Lage AC, Pessoa MC, Velásquez Meléndez JG. Fatores associados à não realização do Teste de Papanicolaou em Belo Horizonte, Minas Gerais, 2008. Rev Min Enferm. 2013;17(03):565-576 